\title{
LAS ELECCIONES PRESIDENCIALES EN ARGENTINA: ¿MENEMISMO O VICTORIA DE MENEM?*
}

\author{
Gabriela Delamata**
}

El día 14 de mayo se celebraron elecciones presidenciales en Argentina. Con un porcentaje del $49.92 \%$ de los sufragios, que superó en tres puntos al de su victoria en 1989, Menem renovó su cargo presidencial por un período de cuatro años. Le siguieron en cifras la fórmula Bordón-Alvarez del Frente País Solidario (29.29\%) y Massaccesi-Hernández por la Unión Cívica Radical $(16.99 \%)(1)$.

Tres son las tendencias que ilustran los datos: la consolidación del liderazgo de Menem, el importante crecimiento de la coalición Frepaso y el fuerte retroceso de la Unión Cívica Radical (2).

Sobre la base de estos antecedentes, trataremos en el presente artículo las cuestiones siguientes: la estabilidad del voto "menemista", el perfilamiento de una alternativa política representada por el Frepaso y, por último, la regresión de la UCR (3); es decir, y en términos generales, nos preguntaremos por el significado y, por tanto, por el carácter efectivamente tendencial o no de las disposiciones políticas anotadas.

* Este trabajo fue finalizado el dia 7 de junio de 1995.

** Licenciada en Ciencias Políticas por la Universidad de Buenos Aires Becaria del Consejo Superior de Investigaciones Cientificas, Madrid.

1. Según datos proporcionados por el Senado de la Nación; el resto de los que aqui exponemos para 1995 tiene carácter no oficial y fue recogido de la prensa argentina. La fórmula del ex-teniente coronel carapintada Aldo Rico (MODIN) obtuvo un $17.8 \%$ de los votos $-\mathrm{y}$ las formaciones de izquierda en su conjunto, el $1.62 \%$ (ambos bajaron estrepitosamente). Los resultados presidenciales tuvieron reflejos dispares para el Frepaso y los radicales en el resto de las elecciones celebradas: en las elecciones a diputados nacionales la fórmula ganadora (Justicialista) se adjudicó un $43.01 \%$ de votos, la UCR un $21.77 \%$ y el Frepaso el $21.23 \%$ de los sufragios; en las elecciones a gobernadores realizadas en 14 provincias, el justicialismo venció en diez y el radicalismo retuvo sus cuatro gobernaciones (Córdoba, Chubut, Catamarca y Rio Negro). También se efectuaron elecciones de diputados provinciales y elecciones municipales. El Frepaso no consiguió ninguna gobernación y tampoco intendencias.

2. De la nueva composición de la Cámara resulta, no obstante, otra correlación de fuerzas: PJ: 133 diputados (alcanzó la mayoria absoluta; UCR: 70 diputados (perdió 13 bancas); y Frepaso: 27 (renovaba sólo 7 bancas frente a las 62 salientes del Justicialismo y 42 de la UCR).

3. Cómo este trabajo discutirá la emergencia de nuevas identidades politicas, la referencia al Radicalismo será más exigua - en parte por razones obvias, en parte por los motivos que apuntaremos en su momento.

\section{EL "MENEMISMO"}

La consolidación del liderazgo de Menem (4), certificada en las pasadas elecciones, podría suponer el comienzo de una nueva $-\mathrm{y}$ para algunos, no tan nueva — forma de hacer política, y atento a sus índices de legitimidad electoral, de una forma ampliamente aceptada y solicitada de concebir el orden político.

Durante los años de su mandato, la popularidad de Menem ha sido atribuida a diversos factores.

En primer lugar, a su capacidad para revertir lo que ha sido por décadas la dinámica más destructora de ingresos y destructiva de la convivencia en Argentina: la hiperinflación - y su vivencia trágica en 1989, en los perentorios días de Alfonsín.

En segundo término, debido a su disposición a gobernar frente a la anterior experiencia radical de pérdida de la autoridad estatal, impotencia y cambio sucesivo de planes.

En tercer lugar, en razón de gobernar de acuerdo con el único modelo adecuado al "humor de época", socializado mediante la codificación al sentido común de los imperativos y las virtudes de aquél (5).

En cuarto lugar, el estilo "menemista", como extensión gestual y simbólica del partido que representa (más allá de las "traiciones", el voto a Menem conserva un importantísimo porcentaje de peronistas "históricos").

En último término, aunque no los agota, su excelente desempeño en los medios de comunicación, a través del cual habría logrado crear un canal de diálogo transparente, fluido y masivo con la población.

$\mathrm{Al}$ parecer, todos estos factores tienen parte de razón, pero ninguno explica por sí la continuada popularidad de Menem.

La disquisición puede no ser banal si se piensa, por el contrario, en cierta homogeneización de las preferencias como explicación posible de la estabilidad (y crecimien-

4. Recordemos que la emergencia y persistencia de liderazgos politicos y anti-políticos no es un fenómeno peculiar de Argentina, sino que puede entenderse a interior de un número de casos - americanos y europeos - más amplio.

5. La "modernización" no sólo se lleva a cabo con fundamento en la ortodoxia económica neoliberal, sino que se lee y se legitima en las dimensiones culturales y politicas del modelo. Asi, deviene de sentido común plantear la dicotomía: privado $=$ bueno, eficiente, transparente, justo/estatal = malo, "burocrático", corrupto, parcial 
to) (6) del voto "menemista" en un contexto generalizado de crisis de las identidades políticas.

En esta tesitura, la permanencia del apoyo a la gestión de Menem podría estar dando cuenta del pasaje de una situación de desidentificaciones partidistas a otra de recomposición de las identidades, esta vez, de tipo personal y contenidos pragmáticos (7). Para entendernos, mientras que la popularidad de Menem estaría asociada, digamos, entre 1991 y 1993, a sintomas de la crisis de las identidades partidistas (de alli la múltiple procedencia/motivación de su voto, su carácter no ideológico y en general, su correlación positiva con la huida del pasado), su estabilidad en el tiempo, en cambio, estaría asociada a la superación de aquel estadio: a una transformación de las viejas identidades politicas —en un sentido no partidista.

Sobre la crisis de las identidades partidistas se ha escrito mucho y no quisiéramos reiterar aquí, una vez más, aquellos análisis (8). Simplemente diremos que tal crisis hace referencia a la merma y/o pérdida de identificación de los ciudadanos con aquellos partidos que hasta el momento constituian su referente de acción. En nuestro caso, el desgaste del voto radical representa el caso más patente de desidentificación partidista. Debida fundamentalmente a la percepción social de baja eficacia decisional y de resultados del gobierno radical frente a la crisis económica, la estrategia pactista de Alfonsín - para la reforma constitucionaly el decaimiento del rol opositor del partido en los años de Menem habrían terminado por minarle casi toda credibilidad (9).

En el peronismo, por otro lado, la desidentificación de sus votantes con el partido se muestra con un formato diferente: en este caso se trataría de un partido que ha perdido parte de su electorado ideológico (debido al giro estratégico de sus dirigentes) pero que aparece, en su estructuración post-renovadora, como una alternativa confiable para canalizar el voto de peronistas "traicionados" en sus ideas o afectados por el ajuste realizado por Menem (baja identificación "tradicional" y -relativamente- alta confiabilidad).

La línea de argumentación que venimos proponiendo es la que va desde esta coyuntura identitaria crítica hacia la conformación de una identidad nueva bajo el "menemismo". Insistiremos en esta conjetura.

6. En las elecciones presidenciales de 1989 la förmula justicialista obtiene el $47 \%$ de los votos, en las legislativas de 1991 , el $40 \%$, en las elecciones legislativas de 1993 , el $43 \%$ de los sufragios, en la elección de constituyentes en 1994 , el $37.7 \%$ y en 1995 , el $49.9 \%$ de los sufragios.

7. Estos se verian reducidos a una demanda de gobierno del tipc: no importa cuáles sean los principios que guian su acción, pero "que gobierne". Las demandas concretas dejan de ser previas o independientes para volverse determinadas por las ofertas del lider (Marcos Novaro: "Crisis de representación, neopopulismo y consolidación democrática", en Sociedad, n. 9 5, 1995, p. 108).

8. Mencionaremos dos trabajos: Ludolfo Paramio: "Consolidación democrática, desafección política y neoliberalismo", en Cuadernos del CLAEH, n. ${ }^{9} 68,1993 / 4$; y Norbert Lechner: "La reestructuración de los mapas políticos", mimeo, México, FLACSO, 1994. Ambos analizan la desafección partidista a partir de contextos más amplios: el cambio de las reglas del modelo de acumulación y las mutaciones en la cultura politica, respectivamente.

9. El partido radical triunfa en las elecciones presidenciales de 1983 con un $51.74 \%$ de los sufragios. La erosión de su voto es muy clara en las elecciones legislativas de $1987(37 \%)$ y aumenta aceleradamente desde entonces: en 1989, logra el $32.40 \%$, en las parciales de 1991 , el $23 \%$, en las también parciales de 1993 , el $30.2 \%$, en la elección de constituyentes de 1994 , el $20 \%$ y en 1995 , el $16.9 \%$.
La profundidad y extensión del cambio politico introducido por Menem es una conclusión a la que han llegado recientemente algunos analistas de su estilo político (10). Partiendo de una situación generalizada y terminal de debilitamiento y fragmentación de las identidades políticas, producto de aquella merma en la credibilidad de los partidos que apuntamos, el "menemismo", como estilo político capaz de adaptarse a tales circunstancias, habría logrado recomponer la fragmentación política y la desarticulación sistémica en una identidad política de nuevo cuño. Se trataría de una identidad personal-nacional: articulada desde el líder por arriba de los sectores dispersos, representaría el interés nacional (de unos actores dispuestos a postergar sus intereses particulares), al mismo tiempo, encarnado en su figura (11).

Pero además, en tanto estamos en presencia de una crisis del mapa identitario global (que afecta por igual a los partidos tradicionales), este tipo de identificación política inaugurada con Menem se multiplicaría de modo tal que definiría una nueva etapa de constitución de los mapas interpretativos de la sociedad. Estariamos frente a nuevas formas de identidad y, por tanto, de relaciones políticas.

Entre otras cosas, hay dos aspectos "tradicionales" en la formación de identidades políticas que dejariamos atrás. Uno de ellos es el reconocimiento intersubjetivo que supone para los miembros el participar de una misma identidad política, el "nosotros". Un momento simultáneo a éste, sería el de la definición de una diferencia (no necesariamente antagónica) respecto de la cual es posible aquel reconocimiento intersubjetivo de los miembros.

Un segundo aspecto "a eliminar" sería el contenido del vínculo que se establece entre los miembros de la identidad y su líder. Porque el pragmatismo que guía esta relación en las nuevas identidades supone el vaciamiento de los que han sido sus contenidos tradicionales: la ideología o el carisma del líder.

¿Será por fin éste, el cambio político producido por el "menemismo" y, prospectivamente, un avance de las tendencias políticas futuras? La respuesta afirmativa se sustenta en la estabilidad del voto "menemista" como prueba de la eficacia y credibilidad en la reconstrucción de las identidades disueltas efectuada por el actual presidente.

La respuesta negativa puede provenir de la exposición de dos argumentos: en primer lugar, un análisís del voto "menemista" en las pasadas elecciones; en segundo término, una revisión práctica del modo como se construyen y se estabilizan las identidades políticas.

1. Con los datos que contamos hasta el momento, el amplio triunfo de Menem en las pasadas elecciones presidenciales sólo podría entenderse como sumatoria de votos más o menos estratégicos. Tendríamos tres formatos de voto: el voto peronista, el voto "Duhalde" y el voto "miedo", en total aproximado un $40 \%$ de los sufragios "menemistas".

10. De allí que se hable directamente del "fenómeno Menem", "menemismo", neo-populismo.

11. La implicación prescriptiva de esta matriz es que la delegación constante (estable) de la voluntad política en el actual presidente indicaria no solamente el refrendo sistemático a su gestión sino, fundamentalmente, el reconocimiento colectivo en su discurso y práctica política. 
Siendo el primer formato el de presunta cuantía menor (es decir, el voto histórico), los otros dos no aparecen motivados por el imaginario peronista, al menos como móvil privilegiado en el orden de preferencias personal: decimos esto porque es en este conjunto estratégico que aparecen los sectores más afectados por la política económica de Menem, que habían sido peronistas "del 45" y que efectivamente votaron por el candidato justicialista Menem en 1995. Precisamente, son estos electores los que engrosan mayoritariamente las filas del voto "Duhalde" (12). Esta denominación no sólo es de origen sino que engloba situaciones análogas: se refiere a los sectores cuya opción electoral parece estar en correlación con los bienes que vienen recibiendo del ejecutivo de la provincia de Buenos Aires (cuyo gobernador es Eduardo Duhalde, del partido Justicialista) a través de planes nutricionales y de autoconstrucción de viviendas (13), y situaciones parecidas en otras provincias provocadas por la inyección puntual de fondos nacionales a través de los ejecutivos provinciales.

Con respecto a estos sectores específicos, algunas encuestas precomiciales habían previsto el corte de boleta electoral en perjuicio de la candidatura de Menem en el nivel nacional: se pensaba en un claro voto de castigo a sus resultados económicos. Sin embargo, pasadas las elecciones, la proyección no resultó confirmada (14): la motivación propia del tercer sector de votantes "menemistas" operó con fuerza también para que los electores de Duhalde en la provincia lo fueran a su vez de Menem. Lo que pareció haber vinculado el voto provincial al voto nacional fue la memoria de los saqueos y el dasabastecimiento de los luego- últimos días de Alfonsín y el resguardo que está significando en los hechos el presente, de que ello no se repita (15).

Esta memoria y esta certidumbre mínima definirian, por último, la principal motivación del voto que hemos denominado "del miedo". En efecto, una parte de las clases medias y la clase baja optaron por conservar lo que poseian frente a cualquier cambio imaginable: ha actuado el miedo pavoroso hacia el pasado (la hiperinflación) y ha actuado a la vez el temor a cualquier modificación del estado de cosas

12. El mismo tipo de voto engloba a sectores recientemente pauperizados del primer cordón poblacional del conurbano bonaerense que solian votar radical

13. Mediante el plan VIDA se entregan alimentos a las familias del conurbano bonaerense (doble cordón que rodea la Capital Federal), y mediante el Plan de Viviendas se gestiona la autoconstrucción de 300 unidades mediante préstamos graciables. Un tercer elemento de ayuda consiste en la atención y resolución personalizada de las necesidades particulares de los vecinos del conurbano. Un dato fundamental a tener en cuenta es que en esta zona de la provincia de Buenos Aires se sitúa el mayor indice de pobres de todo el pais: un $30 \%$ de la población son pobres y el $20 \%$ está desocupada o subocupada. Por su parte, los fondos destinados a asegurar minimos nutricionales y otras necesidades básicas a esta población, alcanzan los 600 millones de pesos al año, el equivalente al $10 \%$ del Impuesto al Valor Agregado nacional. Sobre este tema in extenso puede consultarse Fabián Repetto: "Argentina y la fragmentación excluyente: origenes, consecuencias (Reflexiones sobre los impactos del nuevo vínculo entre Estado y sociedad)", mimeo, FLACSO, México, 1994.

14. El gobernador renovó su cargo con un $56.10 \%$ de los votos a su favor. En la misma provincia de Buenos Aires, Menem obtuvo un $51.3 \%$ de sufragios. Esto indica que Duhalde sólo "superó" a Menem en 5 puntos.

15. Aún quedaria otra posibilidad para explicar el voto "sábana" en estos sectores: que hayan votado a Menem porque él — también - representa para ellos lo que siempre ha sido el sustrato peronista, las politicas de beneficio social. En cualquiera de los dos casos es clara la continuidad de una relación clientelar, populista de estos sectores con el Estado y su peso especifico a la hora de decidir el voto. Otra cuestión es, además, la voluntad del Ejecutivo de no modificar este tipo de relación. en el futuro. Lo primero genera estupor; lo segundo, incertidumbre.

Aún quedaría por sumar, en este apretado resumen, el voto de aquellos sectores cuya identidad, por cierto, parece ser la menos erosionada ya que ha encontrado rápida reafirmación en la apuesta neoliberal de la gestión de Menen: se trata de las clases media alta y alta que representan aproximadamente ese otro $9 \%$ del voto "menemista" no computado en el $40 \%$ al que nos referimos precedentemente.

En términos globales, puede apreciarse que el voto a Menem es menos "menemista" que lo que podría parecer, es decir, que lejos de expresar un fenómeno político univoco, lo que trasluce es una fuerte segmentación motivacional: voto tradicional; voto - llamémosle-clientelar en las zonas donde las condiciones de vida y los efectos del ajuste son más duros; voto conservador en particular y en general; voto liberal. Y además, que la motivación favorita, prevaleciente, con un recorrido transversal en la sociedad, es la más provisoria de todas, es decir, está sujeta a que la estimación coyuntural de las circunstancias económicas continúe siendo la misma: que la estabilidad económica siga siendo el "techo" preferible a cualquier otra situación (16) (que no se transforme en el "suelo" de las expectativas o que, siendo el mínimo deseable, comience a no ser aceptada a cualquier precio) (17).

2. Si un análisis de los resultados electorales nos impide constatar un cierto reconocimiento intersubjetivo entre sus votantes, es decir, la emergencia de un sentido político compartido, reflejado en el voto, la pertinencia de una nueva identidad política de estos heterogéneos sectores podría, en cambio, situarse en la otra relación donde sedimentan las identificaciones políticas.

En efecto, y según lo hemos señalado, la novedad de la nueva identidad política residiría, más que en la formación de un "nosotros", en el vínculo vertical que el lider logra establecer con sus seguidores.

¿De qué tipo sería ese vínculo? En principio, ya hemos descartado una posibilidad: la existencia de un interés nacional de la población que se encarna o personifica en el líder. La segmentación del voto "menemista" es contradictorio con la sustanciación de un interés nacional. A no ser que lleguemos a esa conclusión por la vía de una abstracción brutal, un interés nacional de todos no es evidente. Lo concreto es la simultaneidad de más de diez millones de votos tácticos.

Otra posibilidad anulada desde el comienzo es la identificación ideológica: probable en el caso de los estratos sociales más altos, es su contrario, la desidentificación ideológica o partidista, lo que prima en el resto de la sociedad abriendo el paso a identificaciones de nuevo cuño.

Por fin, nos resta por considerar como vínculo de articulación política entre el líder y sus electores, el carisma.

16. Esto parece poco probable a corto plazo. Lo posible es que la estabilidad se comience a dar por segura y al mismo tiempo insuficiente, lo cual alentaria el surgimiento de expectativas nuevas.

17. Al precio de unas desigualdades sociales crecientes, de la corrupción, de la conducta autoritaria del Ejecutivo. Estas últimas valoraciones ya han aparecido y están en relación directa con el avance electoral del Frepaso, al cual nos referiremos más adelante. 
Como se sabe, el liderazgo es algo que se construye socialmente- y que no puede darse por sentado. Quienes se identifican con una persona se reconocen en algún "elemento" suyo: en la representación del interés nacional que detenta, en su ideario. Lo mismo ocurre con el carisma: éste supone el reconocimiento por sus seguidores de ciertas condiciones excepcionales en el líder (18).

Normalmente, y aunque la emergencia de un líder carismático parece ser de lo más excepcional, su existencia está ligada a la constitución de un doble vínculo: por una parte, es necesario que el discurso del líder sea reconocido por sus seguidores de tal forma que se piensen incluidos en él (aunque ocupando, conscientemente, un lugar subordinado) y de modo que dicho discurso tenga relación tanto con las circunstancias que los rodean como con las prácticas que realizan o pueden realizar sus seguidores. En segundo lugar, y una vez constituido este vínculo, se posicionará el líder como tal, munido de criterios de verdad, de estética, en virtud de los cuales devendrá indiscutido su carisma (19).

En el caso de Menem parece ciertamente temerario calificarlo como líder carismático. Su discurso está bien asentado en el imperio de la necesidad y su paliativo, el constante despliegue de referencias religiosas y trascendentes que realiza, no cierra sino que agudiza la brecha simbólica que instala el pragmatismo como guía para la acción.

Su visibilidad o las intervenciones de cariz mágico que realiza tendrían poca relación con el sentido político que le otorgan o dejan de otorgarle quienes aluden a él; no lo politizan. Las últimas elecciones son paradigmáticas en este sentido: el triunfo electoral de Menem transcurrió en un contexto de pasividad generalizada, donde la sensación de tranquilidad reemplazaba potenciales manifestaciones de júbilo.

Es decir, una cosa es que el mensaje de Menem pueda o no obtener reconocimiento, y otra bastante distinta es que él "confie" en su capacidad propia para interpretar los anhelos de sus electores (20).

En resumen, no parece constatable la emergencia de una identidad política que sustancie la relación entre los desarticulados sectores de la sociedad y la figura de Menem como líder virtual.

Lo que, en cambio, es evidente es que alguna relación sí existe y que su centralidad es indiscutible. La renovación de su mandato así lo indica, pero no indica mucho más, es decir, la presencia de una matriz constitutiva de un nuevo universo político.

18. Sólo unos pocos especialistas han puesto suficiente acento sobre las prácticas de reconocimiento como constitutivas de la eficacia de un discurso. Contra una tendencia bastante acendrada, hay que decir que un relato, un gesto, una persona por sí solos no bastan para producir efectos de identificación.

19. Véase Emilio De Ipola: Ideologia y discurso populista, México, Plaza \& Janés, 1987 , pp. 128-130.

20. Entre sus frases recurrentes, encontramos ésta: "Siempre se ha dicho que soy un intuitivo. Y la intuición es una suerte de actitud, yo diria de fe" (Carlos Menem, La Nación Revista, abril, 1995). Pero aún en estos términos, ¿cuán creible puede ser su rol de intérprete?; en 1993, Menem habia dicho lo siguiente: "Las tres reglas de oro de la conducción son: 1) estar perfectamente informado; 2) guardar en secreto esa información; y, 3) actuar de sorpresa. Es lo que yo hice toda mi vida. Si yo en la campaña electoral le digo a la gente 'Vamos a reanudar las relaciones con Inglaterra', pierdo un 20 por ciento de votos. Si le digo a la gente: "Voy a privatizar teléfonos, ferrocarriles y Aerolineas', tengo en contra todo el movimiento obrero..." (Revista Gente, 1 de abril de 1993)
La efectividad de Menem a la hora de fijar coordenadas vitales está en relación directa con la convalidación de su gestión y su crédito hacia el futuro. La consecución de estabilidad económica ha significado nada menos que devolver al sentido común universal lo que fueran las ideas sobre el tiempo y el espacio en Argentina hasta 1989: superar un pasado (por pasado), vivir ciertamente el presente y prever siquiera un horizonte sin adelantar - inflación medianteconstantemente el futuro. A la vez, diseñar un espacio de reglas mínimas compartidas donde los intercambios (y no la guerra) entre los actores son factibles. Menem ha sabido hacerlo y ello le ha otorgado éxito.

No vamos aquí a aventurar si eso basta para revalidar su legitimidad en el futuro (21); en cambio, proponemos destacar la condición instrumental de Menem para concretar una demanda social generalizada que surge, concretamente, en los últimos años de Alfonsín, cuando el mundo de la economía coloniza la sensibilidad política de los electores. Consistentemente entonces, la creación de certidumbre económica funcionó como motivación fundamental del voto a Menem, pero en un contexto pre-figurado en el cual la demanda de estabilidad aparecía a la vez como condición necesaria para la convalidación de cualquiera otra hipotética gestión.

La capacidad de Menem para satisfacer esta demanda concreta puede que lo eleve a la categoría de líder (en algún sentido, lo suyo es considerado heroico), pero en cualquier caso se trataría de un líder instrumental.

Parece evidente que esta otra comprensión instrumental del liderazgo de Menem puede refutar nuestra conjetura acerca de la institución de una nueva identidad política. Un cambio de expectativas generalizado sería capaz de acabar bruscamente con su liderazgo en futuras elecciones. Pero un cambio de expectativas requeriría un paso adelante en la reconstrucción de las identidades.

Es aquí donde volvemos al principio: ante el desdibujamiento y la "orfandad de códigos interpretativos" que resulta de la erosión y quiebra de las lealtades partidistas, un nuevo "mapa" (22) de discernimiento y orientación politicas requiere, al menos, tiempo. Pero puesto que aquel desdibujamiento no se traduce en una situación de anomia, sino más bien en la pérdida de las certezas de antaño, la coyuntura aparece provista de una serie de "mojones", privados o públicos, que entretanto representan para los electores las ofertas más confiables (23).

La desafección política de muchos sectores repliega su manifestación pública como defensa de los intereses privados. Para ellos es confiable la oferta que cumpla el requisito de la utilidad. La preferencia por un líder que sea, en este sentido, efectivo pero también poderoso, es probable.

21. En vez de ello, proponemos algunos datos y conjeturas: del total de votos obtenidos por Menem a nivel nacional, el $43 \%$ aproximadamente, provino de la provincia de Buenos Aires. En Rosario, donde el desempleo ha crecido más aceleradamente - aqui si desprovisto de politicas de asistencia social-, el Frepaso aumentó fuertemente su caudal electoral. Esto podría ser un indicador de cuán "atado" está el proyecto presidencial a la producción de bienes sociales concretos, la cual no está garantizada con la estabilidad conseguida ni puede soslayarse acudiendo a mera producción simbólica.

22. Ambos entrecomillados son de N. Lechner, art. cit.

23. La confianza "salda" momentáneamente la crisis de representación, pero no provee un marco de estabilidad para las preferencias. 
Las viejas identidades partidistas parecen sobrevivir _ólo- como defensa de la identidad social de sectores más bien minoritarios; siendo refugios seguros para actitudes - también- defensivas, su capacidad para re-posicionarse como fuentes de legitimación plausibles del proceso de cambio económico se muestra, en cambio y por el momento, muy restringida.

Por otra parte, la emergencia de nuevos movimientos políticos con formas más o menos partidistas estaria señalando cierta articulación de demandas sociales que el sistema institucional en su conjunto no logra (o se resiste a) procesar.

Este conjunto heterogéneo de conductas expresa la autonomía de los ciudadanos respecto del sistema de partidos existente pero no recrea un criterio compartido sobre el cual fundar nuevas identidades políticas — sean éstas realmente novedosas o la reconversión de las tradicionales.

Mientras éste no aparezca en el horizonte de los actores será muy dificil prever pautas ciertas de reconstrucción de la ecologia política, y por tanto dar por sentadas identidades políticas que, de momento, sólo redundan en identificaciones de condición efímera (24).

\section{EL AVANCE DEL FREPASO}

Es en este contexto de crisis de las identidades y acción instrumental de los actores donde debe situarse nuestro segundo tema de comentario anotado al comienzo: el crecimiento del Frepaso. Haremos un repaso breve a su incursión en la vida política del país y a sus características, para luego interrogarnos acerca de la constitución de una identidad política — que se habría ido afirmando y extendiendo, como dejan entrever los resultados electorales (25).

Las elecciones para convencionales constituyentes (para la reforma de la Constitución Nacional) celebradas el 10 de abril de 1994 revelaron el fuerte crecimiento del Frente

24. El momento de la catarsis se halla, bien es cierto, condicionado por elementos culturales y estructurales; sin embargo, seria adelantarse a los acontecimientos afirmar que se trata de componentes determinantes en la conformación de las identidades politicas. Algunos de los condicionantes culturales son la tendencia a erigi vínculos clientelares, la institución de fuertes liderazgos como soporte necesario de interpelaciones reconocibles, la centralidad del Estado como locus articulador. Los condicionantes estructurales, por su parte, son aquellos que se derivan tanto de la propia crisis del modelo sustitutivo como de las estrategias gubernamentales para afrontarla: en el contexto de desorganización sistémica y pérdida de racionalidad colectiva en que aquélla desemboca, el espacio de la acción politica se desplaza hacia arriba - hacia el Estado y las élites que lo "habitan"-, hacia el único ámbito donde es inmediatamente posible la creación politica. Pero además, el crédito que la crisis otorga a la discrecionalidad politica se afirma radicalmente cuando las estrategias para su resolución se nuclean en torno un decisionismo desligado de la representación social y sólo dispuesto a respetar ciertas reglas mínimas del juego democrático. Respecto de estos últimos condicionantes, pueden verse, desde perspectivas distintas, Juan Carlos Torre: "América Latina. El Gobierno de la democracia en tiempos dificiles", en Revista de Estudios Politicos, n.. 74, 1991; y Diego M. Raus: "La paradoja latinoamericana: politicas no neoconservadoras y politicas neoconservadoras del orden social", en Documentos EURAL, n.․ 58, 1993.

25. Existen otros temas de sumo interés en lo que se refiere al Frepaso: sus posibilidades de institucionalización partidista y la conformación de un sistema de partidos de nuevo formato. No trataremos aqui estas cuestiones que requeririan apartados propios y suficiente espacio; sobre ellas, recomendamos los articulos relativos publicados en Ciudad Futura, n. 90 y 41 , primavera y verano de 1994, respectivamente.
Grande (antecedente del Frepaso) a la vez que su posicionamiento como única fuerza que parecía realmente desafiar la hegemonía del oficialismo (26). En esa oportunidad, el Frente obtuvo el $13.6 \%$ de los votos a nivel nacional (27), quedando tercero detrás del Partido Justicialista (37.7\%) y del Radicalismo (19.8\%). Pero los resultados fueron más asombrosos aún en Capital Federal donde el Frente logró ubicarse en primer lugar con un $37.6 \%$ de los sufragios (el Justicialismo obtuvo el $24.5 \%$ y la UCR, el $15.2 \%$ ). En unas elecciones peculiares, carentes de resultados visualizables a corto plazo, el Frente Grande conseguía alterar significativamente el mapa electoral y la correlación de fuerzas en él (28).

Con este precedente, las elecciones de 1995 representan un avance importante del -ahora- Frepaso a nivel nacional $(29.29 \%)$ y la estabilización cuantitativa de su voto en Capital Federal (44\% en elección a presidente y 34.7 en elección a diputados, frente a los porcentajes respectivos del PJ y la UCR: 41/22.9 y 10.6/20.3) (29)

En su confirmación actual, el Frepaso aparece integrado por experonistas disidentes del "Grupo de los Ocho" y sectores de izquierda moderada (ambos representados en la figura prominente de Chacho Alvarez), un sector del Partido Comunista (en conjunto, el Frente Grande), la Unidad Socialista (que lidera Alfredo Bravo), y el PAIS, de raices peronistas-socialcristianas, representado por José Bordón; alianza que se fragua con anterioridad a las pasadas elecciones (30).

La pregunta que planteamos a partir de estos pocos datos tiene tres partes: en primer lugar, cuál es la identidad política del Frente, como unidad orgánica; en segundo término, cuáles son las expectativas de sus votantes, y por último, si puede hablarse de la institución de una identidad política amplia compartida por unos y otros.

El interrogante inicial está estrechamente ligado a la conformación interna del Frepaso. Se aduce que el frente interno de la alianza responde a demasiados referentes como para imponer su unidad, y adicionalmente, que el pre-

26. Como se sabe, estas elecciones estuvieron precedidas por el pacto entre Menem y Alfonsin que definía los contenidos más relevantes de la reforma constitucional. Tal como quedaron estipulados, ellos permitirian la re-elección de Menem (expresamente proscrita en la Constitución entonces vigente) y $\longrightarrow$ a cambio- el mantenimiento del sistema bipartidista, con posibilidades claras para el Radicalismo de ganar en una eventual segunda vuelta -institución del ballotage mediante. Ante la opinión pública, la transacción habria colocado al Radicalismo de un mismo lado junto con el oficialismo.

27. Fue primero en Capital y en la provincia de Neuquén, segundo en Buenos Aires y consiguió resultados importantes en Santa Fe y Entre Rios.

28. En las elecciones parciales de 1993, el Frente Grande había conseguido el $3.6 \%$ de los votos, el Justicialismo habia obtenido el $43 \%$ y el Radicalismo, el $30.2 \%$; en Capital Federal, los porcentajes habian sido: 13.6\% para el Frente Grande, 32.5\% para el Justicialismo y $29.9 \%$ para el Partido Radical

29. El voto a presidente por provincias ilustra el avance nacional del Frente: de las 24 provincias, quedó en segundo lugar en diez de ellas con una media entre $20 \%$ y $38 \%$ de los votos. Deben destacarse, el segundo lugar que consiguió en la provincia de Buenos Aires, tanto en la elección a presidente como en la de diputados nacionales y en la de gobernador, y su buena performance, además de Capital, en la ciudad de Rosario. Véanse más datos en nota 1 .

30. Es decir, que surge como alianza electoral de cara a las presidenciales. No obstante, cuenta con un caudal politico (y electoral) previo, acumulado a partir de las acciones que desarrolla el predecesor Frente Grande contra la corrupción y los excesos de poder de la gestión de Menem. Por otra parte, el acompanamiento de los sectores más combativos del sindicalismo (agrupados en la CTA) es constante a lo largo de la vida del frente. 
dominio de la corriente peronista se traduciría finalmente en una "remake" de procedimientos y valores ligados al imaginario justicialista histórico — como lo probaría la visibilidad excluyente del binomio Bordón-Alvarez. En estos términos, no habria tal novedad política detentada por el Frepaso, sino la reconstitución de un peronismo ("el verdadero") enfrentado al que ostentan Menen y los suyos.

La objeción es cierta si se enfoca la cuestión desde un plano estático: ella sitúa el visor sobre tradiciones políticas muy disímiles e históricamente rivales entre sí, e intuye la también histórica predominancia del justicialismo frente al accionar "meramente declarativo" de la izquierda.

Pero resulta que, precisamente, en las prácticas iniciales del Frepaso (entonces FG), en su debut en las constituyentes del 94, el tono que éste imponía lo colocaba en la antítesis de los componentes culturales que habían definido históricamente a sus diferenciadas fuerzas: el valor de los procedimientos democráticos contra la lógica política del populismo y el cambio radical (31). La cohesión política se conseguía mediante el incentivo de superar la tradicional hegemonía y los desencuentros ideológicos.

Es también correcto afirmar que se trató de una fuerza que logró articularse sólo por oposición a; sin embargo, resulta otra vez verdadero que el modo de plantear el enfrentamiento con el poder resultó ser el núcleo central de su apuesta: lejos de reproducir la estrategia de aquél, actuó en consistencia con los principios republicanos.

A partir de este sentido político compartido, la conflictividad interna, que aparecía más en el plano personal que en el de las ideas, se mantuvo a decibelios bajos (nunca se puso en cuestión la incompatibilidad de la alianza) (32), a la vez que se canalizaban energías hacia el perfilamiento de un discurso de mayor autosuficiencia de cara al 95.

Con anterioridad a la elección para constituyentes, el Frente, con centro en el discurso de Alvarez y las intervenciones de otros dirigentes de la capital, había concentrado su acción en la denuncia política - y en su caso, judicialde los casos de corrupción y del avasallamiento de los poderes constituidos por parte del Ejecutivo. A partir del pacto Menem-Alfonsín fijando de antemano los contenidos de la nueva Constitución, la estrategia del Frente se intensificó, no sólo porque el polo opositor aparecía, ya sin ambages, más explícito, sino porque a ella fue arrastrado por una opinión pública aturdida por el acontecimiento, que a la postre quedaba huérfana del amparo que la retórica radical le proveía contra el abuso de poder.

El pacto creaba un espacio objetivo de oposición, pero éste no podía ser sustanciado sino a partir de la representación de demandas que la transacción de Alfonsín y Menem clausuraba.

$\mathrm{Y}$ es precisamente a partir de la discusión sobre los límites del poder que el Frente instala en aquel momento fundacional, que emerge, en un movimiento de feed back, un sentido ampliado de impugnación del autoritarismo, como opción de la ciudadanía.

31. Cf. Isidoro Cheresky: "Argentina. La innovación política", en Nueva Socie dad, n. 132 , julio-agosto 1994

32. El distanciamiento del grupo liderado por Solanas y otras formaciones de izquierda en ocasión de la Convención Constituyente habia "liberado" al frente de sus corrientes más críticas con la propuesta consensual de Alvarez.
El voto al Frente para la elección de constituyentes puede ser entendido entonces como un voto de rechazo, como un voto negativo, traslúcido de lo que no se quiere más que de lo que se desea, como un voto de oposición puntual más que un voto de alternativa de oposición.

A partir de la Constituyente, el Frente y su público entrarian en un proceso de intercambio y ajuste recíproco de expectativas cuya viabilidad aparecía atada a un cúmulo de circunstancias del contexto: la que más lo facilitaba estaba referida al espacio amplificado con que contaba el Frente para hacer oposición tras la actitud "realista" de Alfonsín; el factor precipitante eran las futuras elecciones presidenciales que lo urgían a definir un proyecto político - presidenciable- para el país; la circunstancia que ofrecía más dificultades era el heterogéneo universo de los votantes y potenciales aliados que sintonizarían o no con el mensaje dependiendo de su posicionamiento respecto de los diferentes intereses individuales y sociales (33).

Dijimos anteriormente que las potenciales dificultades del Frente para superar su disímil conformación interna, y por tanto cohesionar ideas, se vieron decisivamente aminoradas por la urgencia que imponían los tiempos electorales.

Manteniendo el perfil de "unidos contra el poder", el desarrollo del discurso del Frente no llegó a mayores. En el tiempo que medió entre las elecciones del 94 y las pasadas del 95, el originario mensaje del Frepaso amplió su legitimidad pero no alcanzó a fraguar un proyecto político nacional.

Lo conseguido afianzó su presencia política y sus apoyos en una resucitada conciencia democrática, pero al precio de no lograr ser más que eso, un movimiento político que no traspasa la frontera hacia una definición de los intereses sociales que ostenta representar.

En este contexto, ¿qué sentido político otorgar al crecimiento del Frepaso en las recientes elecciones presidenciales?. Nuestra perspectiva vuelve a ser la de intentar una respuesta en el plano de las identidades.

La posibilidad de insistir en un voto de rechazo al exceso de poder que concentra el Ejecutivo, a sus "negociados", a la trivialización de lo público que realiza, parece plausible. En esta tesitura, estaríamos en presencia de una estrategia defensiva recostada sobre un espacio imaginario amenazado en el espectro de los partidos existentes.

Desde esta evaluación, la defensa moral sería especificación de una de las estrategias posibles cuando las viejas identidades declinan y no aparece un principio re-ordenador de la inteligibilidad política: la afirmación de una moralidad propia como reaseguro de supervivencia en el sinsentido que aparece dominando la vida política.

Esta puede ser una versión del asunto. Ella conspiraría contra la idea de la construcción de un referente de pertenencia novedoso, en torno al Frepaso.

La otra posibilidad parte del mismo contexto simbólico crítico que la primera, pero se aparta luego de ella. En efecto, si pensamos que la emergencia de un sentido políti-

33. Las intervenciones públicas de Alvarez combinaron mensajes contradictorios: a veces se aludia a la renovación del peronismo histórico, otras, al costado bueno e irreversible del plan de convertibilidad, en otras circunstancias rozaba la socialdemocracia, aditamento que será más contemplado en la retórica de Bordón. 
co democrático, principista, arrastra tras de sí más de un lustro de desencanto con la política, de desinterés por cómo es practicada, de baja popularidad de las instituciones del régimen (34), de pasiva tolerancia hacia los hechos de corrupción, la incursión - positiva - de aquél en la escena política podría estar dando señales de nuevas identificaciones.

Es más, la denuncia del pacto entre Menem y Alfonsín, como factor activante de nuevos reclamos políticos, podría dejar de evaluarse en los términos en que se viene planteando sistemáticamente, como el flanco débil del movimiento frentista (el sólo "oponerse a"), y pensarse como punto de inicio en la construcción de un antagonismo político sobre el cual comienzan a dibujarse identificaciones políticas más estables.

Esto bien bastaría para proponer la idea de una nueva identidad política germinal. Y aún cuando nos suene a viejo $\mathrm{y}$, con abstracción de las circunstancias y los desafíos de entonces, la emergencia de un partido con estas características nos evoque los orígenes del Radicalismo.

Incluso es probable que ello no sea lo más adecuado hoy, y más cuando nos retrotrae también a la política de enemigos de un pasado no tan lejano.

Sin embargo, no es recurriendo al pasado como deslegitimaríamos, por irrazonable, la idea propuesta. Dado cierto círculo de reconocimiento político en simultaneidad con la definición de un adversario externo, en condiciones iniciales de desidentificación con viejas estructuras partidarias y desinterés por la política, la aparición de una "protoidentidad" parecería factible (35).

No obstante, hay un dato fundamental, que si bien no desmerece en absoluto la existencia de nuevas identificaciones, nos desplaza hacia afuera del espacio de las identidades politicas parciales (partidistas o proto-partidistas), llevándonos a un plano tan importante como augurioso.

Al igual que lo anotábamos para destacar la precariedad de los apoyos a Menem, en el caso del Frepaso, la heterogénea composición de su electorado y su extrema volatilidad se vuelven un indicador de la debilidad de su austero discurso para ostentar la representatividad social de aquellos sectores.

Para las elecciones de 1994, se calculaba que habían votado por el Frente Grande el 45\% de quienes en 1993 habían votado por la UCR, 25\% del MODIN, 25\% de la Unidad Socialista (que por ese entonces no integraba el Frente) y $10 \%$ de la Unión de Centro Democrático (36). En las actuales elecciones y a partir de los resultados podría intuirse, por lo menos, una afluencia importante de votos

34. En 1993, un $60 \%$ de los entrevistados por Mora y Araujo, manifestaba su indiferencia respecto de la politica. El porcentaje de popularidad de las instituciones -parlamento y partidos- rondaba el 10\% (Carballo de Ciley) y la valoración de ineficacia de la Justicia, el 78\% (página 12: 4 de mayo de 1994). Datos extraidos de José Nun: "Populismo, representación y menemismo", en Sociedad, n. ${ }^{2} 5$, octubre 1994.

35. "... no se trata tanto de una identidad política preexistente como de la aparición de una 'protoidentidad', nacida por decantación de experiencias frustradas en combinación con el desencanto respecto del actual estado de la cultura politica en el país", Edgardo Mocca: "El tercero en discordia", en Ciudad Futura, n." 40, primavera, 1994, p. 10.

36. Datos que constan en I. Cheresky, art. cit., p. 18, según encuestas en boca de (antes) radicales, de sectores de izquierda no incorporados al Frente y de quienes votan por primera vez.

Con este tipo de apoyos, mientras la nueva fuerza no articule intereses sociales más específicos en un programa político más integral, su supervivencia como opción política - y electoral- no estará garantizada. Pero esto, no sólo porque se proyecta como un partido político y en tal caso deberá escoger entre serlo o contentarse con el rol aglutinante que le confiere la actual coyuntura, sino sobre todo, porque el flujo de nuevo sentido político instituido en torno a él, no necesitaría de su existencia para sobrevivir (aunque quizás sí de su estímulo).

En sintesis, lo que nos parece atinado aventurar es un cambio importantísimo en la cultura política, una recuperación de los procedimientos democráticos como guía de la acción política, el resurgir de una comunidad de ciudadanos.

Y en esta labor, buena parte le cabe al Frepaso. Lo que queda desdibujado, en cambio, es cuál será su performance en la recreación de un referente de identidad y, si de ese criterio participarán amplios o escuetos sectores de la sociedad.

Aquejado por el mismo "mal" que ronda el liderazgo de Menem, los recursos con los que cuenta para sedimentar solidaridades son imprecisos e inciertos.

Acaso la renovación cultural en torno a un principio democrático de legitimidad del poder opere como ese mínimo de sentido imprescindible a partir del cual reconstruir las identidades partidistas en cuestión.

\section{UCR Y FINAL}

La evaporación del más antiguo partido nacional argentino asombra a propios y extraños. Mientras que unos y otros coinciden en la crisis de credibilidad que lo aqueja desde 1987 como explicación de su consunción, no todos colocan suficiente énfasis sobre los acontecimientos de 1994.

Quizás porque no entra dentro de lo teorizable, el pacto que Alfonsín realizara con Menem, sólo pueda ser valorado en su flanco trágico por propios, y menos por extraños.

En primer lugar, es cierto que el acuerdo declinaba el rol de oposición del Radicalismo: al amigarse con el enemigo rompía el universo dual en el que se concebía la política. Para sus seguidores se desdibujaba el viejo mapa del sentido común. Sin ser despreciable, ello era profundamente traumático.

Lo insoportable viene por el lado de la visibilidad de un acuerdo personal que, fuera de bambalinas y sin debate previo (la historia argentina está llena de complicidades discretas), renunciaba sin explicaciones a la "causa" radical. Los "boinas blancas" podían tolerar $-\mathrm{y}$ aún justificar - la ineficacia en el desempeño económico, pero no la puesta en cuestión de su reserva mor 1 , que les proveía de orgullosa identidad.

El pacto era, en la propia jerga radical, el "contubernio" que en cualquier caso les correspondía a ellos denunciar.

En fin, lo que en otras fuerzas más acostumbradas al realismo político hubiese sido menos urticante, para algunos radicales fue dificil y para muchos imposible de digerir. 
Las ventajas de una reforma constitucional consensuada frente a la posibilidad de su imposición hegemónica y sin límites por parte del oficialismo, no era un argumento creíble en el contexto del pacto. Siendo el fin su reelección, Menem no se oponía a discutir los medios, sino todo lo contrario. Con la cláusula de reelección por descontada, cualquier otra limitación de poder por vía del pacto, sonaba contradictoria con el presunto espíritu que Alfonsín le otorgaba, esto era, precisamente, evitar el enquistamiento de Menem en el poder.

Incluso, las garantías de poder futuro para el partido que según Alfonsín adelantaba el pacto, tampoco eran leídas en esos términos por sus seguidores y parte de la dirigencia: si sobrevivía el aparato, no obstante se diluía la representatividad social.

Desde la Constituyente, cuando el principismo le jugaba una mala pasada a las explicaciones de circunstancia, el Radicalismo ha seguido cayendo. Pero esta vez, la desacumulación política se debe en menor medida a la ineficacia del partido para gobernar o para recuperar el papel de oposición, y en mucho mayor proporción a su falta de legitimidad moral, ya para hacer una cosa o la otra.
Esta breve referencia al partido radical puede servirnos para adicionar algún elemento más a la cuestión de la crisis y recreación de las identidades políticas.

Si hemos querido marcar puntualmente la polémica en torno del pacto como decisiva para la erosión del colectivo radical es porque su significado público está en sintonía con aquel clima más generalizado y más fluido de cambios. Evidentemente, el ineficaz desempeño económico del pasado gobierno radical es muy importante a la hora de evaluar la credibilidad mermada del partido, pero es necesario destacar otro elemento: que presente y futuro también han comenzado a interesar en Argentina. Ya sea en la forma de "salida" o de nuevas expectativas, el momento económico empieza a estar acompasado por el momento político.

Nuevamente, este emergente ambiente político no puede ser premonitorio de un mapa político transformado, así como no puede predecir el derrumbe radical. Entre una coyuntura quizás auspiciosa pero incierta y un mapa político estable, hay aún mucho camino por andar y también, sea dicho, por desandar.

\section{RESUMEN}

Gabriela Delamata realiza un interesante análisis de la política argentina actual, partiendo de los resultados electorales de 1995. Estas elecciones consolidaron el liderazgo del peronista Carlos Menem, ilustraron el sostenido crecimiento de la colación Frepaso desde abril de 1994 y el fuerte retroceso de la Unión Cívica Radical. Sobre estas bases, Delamata reconstruye el sistema político argentino en torno a cuestiones tales como la estabilidad del,voto menemista, la existencia de una política alternativa del Frepaso y la regresión de la UCR.

ABSTRACT
Gabriela Delamata realizes an interesting analysis of the current Argentinian politics starting from the
1995 electoral results. These elections which consolidated the leadership of peronist Carlos Menem,
illustrated the sustained increase of the coalition Frepaso from april 1994 and the strong withdrawal of
Unión Cívica Radical (UCR). Upon these facts, Delamata rebuilds the Argentinian political system
around issues such as the stability of menemist vote, the existence of a political alternative in Frepaso
and the retreat of UCR.

